\title{
Detection and Profiling of Diarrheic Marine Biotoxins in Shellfish by mRNA Analysis of Exposed Caco-2 Cells Using qRT-PCR and Multiplex Magnetic Bead-Based Assays
}

\author{
Marcia Bodero, Toine F. H. Bovee, Liza Portier and Peter J. M. Hendriksen \\ RIKILT Wageningen University \& Research, Wageningen, The Netherlands
}

\begin{abstract}
The mouse bioassay for the detection of marine biotoxins in shellfish products is 40 years old and still in use. A full ban or total replacement of this in vivo test has been postponed because of the fear that current chemical-based detection methods could miss a new emerging toxin. In order to fully replace the mouse bioassay, more efforts are needed in the search for functional assays with specific endpoints. Gene expression elicited by diarrheic shellfish poisons (DSP) in Caco-2 cells allowed us to determine three "DSP profiles", i.e., OA/DTX, AZA-YTX, and PTX profiles. Twelve marker genes were selected to represent the three profiles. QRT-PCR is relatively cheap and easy, and although its multiplex capacity is limited to 5 genes, this was sufficient to show the three expected profiles. The use of the multiplex magnetic bead-based assay was an even better alternative, allowing the detection of all 12 selected marker genes and 2 reference genes, and resulting in clear profiles with for some genes even higher induction factors than obtained by qRT-PCR. When analyzing blank and contaminated shellfish samples with the multiplex magnetic bead-based assay, the contaminated samples could easily be distinguished from the blank samples, and showed the expected profiles. This work is one step further towards the final replacement of the mouse bioassay. We suggest to combine the neuro-2a bioassay for screening with detection by analytical chemical analyses and with the multiplex magnetic bead-based assay for confirmation of known and unknown toxins.
\end{abstract}

\section{Introduction}

Marine biotoxins are toxins produced by phytoplankton and/or bacteria that can accumulate in several types of marine animals, e.g., shellfish, crabs, and fish (FAO, 2004). Bivalve molluscs feed through filtration and concentrate these toxins in their bodies and digestive glands (Botana, 2012; Gerssen et al., 2010a). Mussels, for example, filter 7.5 liters of seawater per hour, from which pollutants and toxins are accumulated and concentrated (Ciminiello and Fattorusso, 2006). When humans consume seafood containing toxins in amounts that exceed the established safety levels, this may lead to intoxication. Marine biotoxins can cause clinical features that vary from diarrhea and amnesia to paralysis and even death. Five groups of marine biotoxins are regulated within the European Union, i.e., okadaic acid group (OA), also known as the diarrheic shellfish poisons (DSPs), which in- cludes the dinophysistoxin analogues (DTXs); azaspiracid group (AZAs), which can also cause diarrhoea; yessotoxin group (YT$\mathrm{Xs}$ ); domoic acid group (DA), also known as amnesic shellfish poisons (ASPs); and saxitoxin group (STXs), also known as paralytic shellfish poisons (PSPs) (EFSA, 2009). These groups include several different types and analogues. Worldwide, algae toxins cause approximately 60,000 human intoxications per year (Van Dolah and Ramsdell, 2001).

In order to prevent intoxications, several countries have legislation regarding permitted levels of the different marine biotoxins in shellfish that need to be checked by monitoring programs. These monitoring programs make use of different methods (Gerssen et al., 2010a). The method used most often worldwide is the mouse bioassay (MBA), where an extract of shellfish is injected intraperitoneally into a number of mice and death is the endpoint that determines whether the sample is safe to consume or not (Garth-
Received May 29, 2018; Accepted November 21, 2018; Epub November 21, 2018; ( The Authors, 2018.

ALTEX 36(2), 203-214. doi:10.14573/altex.1805291

Correspondence: Toine Bovee, PhD, RIKILT Wageningen University \& Research Postbus 230 6700AE, Wageningen, The Netherlands (toine.bovee@wur.nl)
This is an Open Access article distributed under the terms of the Creative Commons Attribution 4.0 International license (http://creativecommons.org/licenses/by/4.0/) which permits unrestricted use, distribution and reproduction in any medium, provided the original work is appropriately cited. 
waite, 2000; Stewart and McLeod, 2014). Besides ethical issues regarding the use of laboratory animals, the MBA is known to have high rates of false-positive and false-negative outcomes (EFSA, 2009; Hess et al., 2006). In Europe, the MBA has been banned since 2015, except for PSP analysis, and the control of production areas to detect the emergence of possible new, unknown toxins (EU, 2011; Rossini, 2005; Campbell et al., 2011). Some countries continue to use the MBA due to a lack of standards for the known toxins. The EU reference method for the detection of lipophilic shellfish toxins (mainly DSPs and AZAs) is the LC-MS/MS method of the European Reference Laboratory (EURL) on marine biotoxins (Gerssen et al., 2010b; EU, 2011).

Where possible, toxicity testing should comply with the $3 \mathrm{R}$ principle, i.e., to refine, reduce, and replace experiments with animals (Denisson and Anderson, 2007; Hess et al., 2006; Combes, 2003). Some cell-based assays have been developed to learn about the mode of action or biological activity of the marine biotoxins and to replace the MBA (Bovee et al., 2011; Bodero et al., 2018b; Rossini, 2005). The neuro-2a assay is considered one of the most promising cell-based bioassays for the broad screening of marine biotoxins, i.e., DSPs, neurotoxic shellfish poisons (NSPs), and PSPs (Cañete and Diogène, 2008; Ledreux et al., 2012; Serandour et al., 2012; Nicolas et al., 2014). The readout of the neuro-2a assay is reduction of MTT (decrease of cell viability) and positive samples should be confirmed by additional LC-MS/MS analysis (Bodero et al., 2018a). However, if a positive sample is not confirmed by analytical chemical methods, it may still contain either a known toxin that cannot be detected by the method or an unknown toxin. In such cases, an additional cell-based bioassay that can confirm the presence of a toxin and identify the toxin type would be very helpful. This could be achieved by a cell-based bioassay with a gene expression readout (Botana, 2012).

To develop such an assay a whole genome mRNA expression analysis using DNA microarrays was performed on the human intestinal Caco-2 cell line exposed to DSPs. Gene expression patterns induced by toxins or other bioactives are specific and commonly used to characterize new compounds, i.e., to compare the profile of the compound with others available in data banks (read across). Exposure of Caco-2 cells to the five regulated DSPs, i.e., OA, DTX-1, AZA-1, PTX-2, and YTX, yielded specific gene expression patterns. From the information provided by these microarray analyses, insights on their mode of action were described for OA, DTX-1, and AZA-1 (Bodero et al., 2018b). In summary, OA and DTX-1 induced almost identical mRNA expression patterns, in agreement with the fact that both molecules are analogues that belong to the same toxin group and cause similar effects. For instance, OA and DTX-1 increased expression of genes involved in the hypoxia induced factor pathway/process (HIF), in line with the inhibition of phosphatases and a subsequent activation of the Akt/mTOR pathway, which is involved in the activation of the HIF. OA and DTX-1 also affected pathways like unfolded protein response (UPR) and endoplasmic reticulum (ER) stress. The mRNA expression pattern of AZA-1 was different and included an increase of genes involved in cholesterol biosynthesis and glycolysis pathways, suggesting a different mode of action (Bodero et al., 2018b). Since full genome microarray analysis is not suitable for rapid screening, alternative platforms to detect gene expression levels of highly up- or down-regulated genes as markers for detection and identification were evaluated. A first approach involved a so-called tube array with a limited number of selected marker genes. The test was rather expensive, labor-intensive, took about 3 days and the sensitivity of several of the selected genes was limited (Bovee et al., 2011).

The present study describes two new approaches to detect marker mRNAs in exposed Caco-2 cells, i.e., a multiplex qRTPCR and a multiplex magnetic bead-based assay. The multiplex qRT-PCR was performed successfully with 5 markers (using the maximum number of 6 fluorescent markers resulted in interference). The multiplex magnetic bead-based assay was able to correctly quantify the expression levels of 12 selected marker genes. The present study shows that detection of marker mRNAs in exposed Caco-2 cells could be a promising tool to confirm the presence of unknown DSPs in mussel samples that were positive in the neuro-2a assay but could not be confirmed by LC-MS/ MS. We thus propose a testing strategy in which the neuro-2a assay is used as a screening method, LC-MS/MS is used to confirm positive samples, and the Caco- 2 based multiplex magnetic bead-based assay is used to confirm the presence of a toxin and detect a toxin profile for samples that are positive in the neuro-2a but cannot be confirmed by LC-MS/MS. This work will contribute to the search for new endpoints to detect known but undetectable and unknown marine biotoxins, and does so without animal testing.

\section{Material and methods}

\section{Reagents and standards}

Certified reference materials (CRMs) of OA $\left(13.7 \pm 0.6 \mu \mathrm{g} \mathrm{m}^{-1}\right)$, DTX-1 $\left(15.1 \pm 1.1 \mu \mathrm{g} \mathrm{ml}^{-1}\right)$, DTX-2 $\left(7.8 \pm 0.4 \mu \mathrm{g} \mathrm{ml}^{-1}\right)$, PTX-2 $\left(4.40 \pm 0.13 \mu \mathrm{g} \mathrm{ml}^{-1}\right)$, AZA-1 $\left(1.24 \pm 0.07 \mu \mathrm{g} \mathrm{ml}^{-1}\right), \mathrm{AZA}-2(1.28 \pm$ $\left.0.05 \mu \mathrm{g} \mathrm{ml}^{-1}\right)$, AZA-3 $\left(1.04 \pm 0.04 \mu \mathrm{g} \mathrm{ml}^{-1}\right)$, YTX $(5.6 \pm 0.2 \mu \mathrm{g}$ $\left.\mathrm{ml}^{-1}\right)$, and hYTX $\left(5.8 \pm 0.3 \mu \mathrm{g} \mathrm{ml}^{-1}\right)$ were purchased from the National Research Council, Institute for Marine Biosciences (NRC CNRC, Halifax, Canada). Pinnatoxin E (PnTX-E) was obtained from Cawthron Institute, New Zealand. Stock solutions of these toxin standards were prepared in dimethyl sulfoxide (DMSO) after evaporation of the original solvent. DMSO and n-hexane were obtained from Merck (Darmstadt, Germany). Methanol (Ultra LC/MS) was purchased from Actu-All (Oss, The Netherlands).

\section{Cell culture}

The human colonic adenocarcinoma cell-line Caco-2 (ATCC, Manassas, VA) was grown in Dulbecco's Modified Eagle Medium (DMEM) obtained from Lonza (Verviers, Belgium) supplemented with $10 \%(\mathrm{v} / \mathrm{v})$ fetal calf serum from Gibco BRL (Fisher Emergo, Landsmeer, The Netherlands), non-essential amino acids (NEAA) from MP Biomedicals (Illkirch, France), and penicillin $0.1 \% \mathrm{v} / \mathrm{v}(50 \mathrm{mg} / \mathrm{ml})$ from Sigma (Zwijndrecht, The Netherlands). The cells were grown in $75 \mathrm{~cm}^{2}$ flasks at $37^{\circ} \mathrm{C}$ and $5 \% \mathrm{CO}_{2}$. 


\section{Samples}

In-house samples, both blank mussel samples from the Netherlands and contaminated samples obtained from various locations in the EU and used for previous validation studies of the LC-MS/ MS method (van den Top et al., 2011) were tested.

\section{Preparation of extracts}

Prior to extraction of the blank samples and the ones containing lipophilic marine biotoxins, shellfish material was homogenized with a T25 Ultra Turrax mixer at 24,000 rpm (IKA ${ }^{\circledR}$ Works Inc., Wilmington, NC, USA). One gram of shellfish homogenate was vortex mixed with $3 \mathrm{ml}$ methanol for $1 \mathrm{~min}$ and centrifuged for $5 \mathrm{~min}$ at $2000 \times \mathrm{g}$. The supernatant was transferred to a volumetric flask and the residue was extracted twice more with $3 \mathrm{ml}$ methanol. After the third extraction the volume of the collected supernatant was adjusted to $10 \mathrm{ml}$ with methanol. For exposure of Caco-2 cells, additional clean-up steps using n-hexane and solid phase extraction (SPE) were applied.

\section{Clean-up by n-hexane wash step followed by SPE}

A $4.8 \mathrm{ml}$ aliquot of the crude methanol shellfish extract was diluted with $1.2 \mathrm{ml}$ Milli-Q water and extracted twice with $6 \mathrm{ml}$ n-hexane in order to remove matrix substances that had been found to lead to false-positive test outcomes (Bodero et al., 2018a). The hexane layer was discarded and the aqueous methanolic extract was further diluted by adding $10 \mathrm{ml}$ Milli-Q water and the total extract of $16 \mathrm{ml}$ was transferred to an SPE StrataTM-X cartridge $(200 \mathrm{mg} / 6 \mathrm{ml}$; Phenomenex, Utrecht, The Netherlands), previously conditioned with $4 \mathrm{ml}$ methanol/ water $(30: 70 \mathrm{v} / \mathrm{v})$. Subsequently, the cartridge was washed with $8 \mathrm{ml}$ methanol/water $(20: 80 \mathrm{v} / \mathrm{v})$ and the toxins were eluted with $4.8 \mathrm{ml}$ methanol. The eluate was evaporated to dryness under a stream of nitrogen gas and reconstituted in $20 \mu \mathrm{l}$ DMSO.

\section{Exposure, RNA isolation, and cDNA synthesis for}

multiplex $q R T-P C R$ analysis

$600 \mu \mathrm{l}$ of Caco- 2 cell suspension were seeded in 24 well plates (Ref. Number 3524, Corning, NY) using $8 \times 10^{4}$ cells per $\mathrm{ml}$ and incubated for $48 \mathrm{~h}$ at $37^{\circ} \mathrm{C}$ and $5 \% \mathrm{CO}_{2}$ to reach $80-90 \%$ confluence. DMSO $0.25 \%(\mathrm{v} / \mathrm{v})$ was included as vehicle control. Exposures were performed in triplicate. Cells were exposed to the standards and samples for $24 \mathrm{~h}$, medium was removed, cells were washed with PBS and lysed with $600 \mu \mathrm{l}$ of RTL buffer containing 1\% $\beta$-mercaptoethanol. RNA was extracted using the QIAshredder and RNeasy Mini Kit (Qiagen, Venlo, The Netherlands) followed by DNAse treatment with RNAse-free DNAse (Qiagen, Venlo, The Netherlands), both by following the instructions of the manufacturer. After the extraction, the amount and quality of the RNA were evaluated by UV spectrophotometry (260 and $280 \mathrm{~nm}$ wavelength) on the Nanodrop spectrophotometer (Nanodrop technologies). cDNA was synthetized using $1 \mu \mathrm{g}$ of RNA per sample and from an "RNA pool mix" of all treatments with and without reverse transcriptase using the Biorad iScript cDNA Synthesis Kit with iScript and reverse Transcript (Biorad, 170-8891) in the BioRad iCycler (Biorad, Veenendaal, The Netherlands). The program used was $5 \mathrm{~min}$ at $25^{\circ} \mathrm{C}, 30 \mathrm{~min}$ at $42^{\circ} \mathrm{C}, 5 \mathrm{~min}$ at $85^{\circ} \mathrm{C}$, after which the samples were placed on ice for $5 \mathrm{~min}$. After cDNA synthesis, the samples were diluted 10 and 100 times and the pool was diluted 10, 31.6, 100, 316, 1000 , and 3160 times and used to make a calibration line. The samples were stored at $-20^{\circ} \mathrm{C}$.

\section{Singleplex qRT-PCR method}

Singleplex qRT-PCR was performed for the selected marker genes with certified QuantiTect primers from Qiagen (Venlo, The Netherlands) using $15 \mu \mathrm{l}$ final volume containing: $8.5 \mu \mathrm{l}$ SYBR green (BioRad 170-8880), $2.5 \mu$ of the QuantiTect forward/reverse primer mix, $2 \mu 1$ RNAse free water, and $2 \mu 1$ of 100x diluted cDNA. Reactions were performed in a BioRad HSP9645 PCR plate. Water and "RNA pool mix without reverse transcriptase" were used as negative controls. The plate was covered with a microseal and centrifuged for $1 \mathrm{~min}$. Thermal cycling was performed in a CFX96 Real-Time System (Biorad), starting with a denaturation step at $95^{\circ} \mathrm{C}$ for $3 \mathrm{~min}$, followed by 45 cycles at $65^{\circ} \mathrm{C}$ with $35 \mathrm{~s}$ for annealing, $10 \mathrm{~s}$ at $95^{\circ} \mathrm{C}$ for denaturation, and $1 \mathrm{~min}$ at $65^{\circ} \mathrm{C}$ for extension. Data were analyzed using BioRad software. Expression ratios of the genes were calculated for exposures versus DMSO control.

\section{Multiplex qRT-PCR method}

Multiplex qRT-PCR was performed with primers as shown in Table 1 from Qiagen (Venlo, The Netherlands) and Biolegio (Nijmegen, The Netherlands). All the probes were provided by Biolegio. The sequences are confidential. The reactions were performed using $25 \mu$ l final volume containing $12.5 \mu 12 x$ Quantifast multiplex PCR master mix (Qiagen, Venlo, The Nether-

Tab. 1: Primers, probes, and dyes selected for the development of a multiplex qRT-PCR

\begin{tabular}{|l|l|l|l|l|}
\hline Gene name & Primers & Specification & Cat number & Probe dye \\
\hline NPPB & Qiagen & Hs_NPPB_1_SG & QT00031934 & 6FAM \\
\hline RGS16 & Biolegio & na & na & Texas Red \\
\hline DDIT4 & Qiagen & Hs_DDIT4_1_SG & QT00238588 & HEX \\
\hline CXCR4 & Qiagen & Hs_CXCR4_2_SG & QT02311841 & Quasar 705 \\
\hline TGFB2 & Biolegio & na & na & Cy5 \\
\hline
\end{tabular}

na: no annotation 
lands, cat number 204752), $1.25 \mu 1$ of each primer probe mix, 3.75 or $6.25 \mu 1$ RNAse free water, and $2 \mu 1$ of 10x diluted cDNA. Reactions were performed in a BioRad HSP9645 PCR plate. Water and "RNA pool mix without reverse transcriptase" were used as negative controls. The plate was covered with a microseal and centrifuged for $1 \mathrm{~min}$. Thermal cycling was performed in a CFX96 Real-Time System (Biorad), starting with an initial denaturation step at $95^{\circ} \mathrm{C}$ for $5 \mathrm{~min}$, followed by 44 cycles at $60^{\circ} \mathrm{C}$ with $45 \mathrm{~s}$ for annealing, $45 \mathrm{~s}$ at $95^{\circ} \mathrm{C}$ for denaturation, and $45 \mathrm{~s}$ at $60^{\circ} \mathrm{C}$ for extension.

Data were analyzed using BioRad software CFX manager v.3.0. Plate set up and standard curve were selected, and the results are shown as $\log 2$ values. Relative quantities $(\Delta \mathrm{Cq})$, which express the quantity of the gene under a certain treatment (toxin) versus the quantity under control treatment (vehicle) are plotted and expressed as $\log 2$ values versus the control. The expression of the reference gene TMEM179B was not affected by any treatment and left out in the newly developed multiplex qRT-PCR method.

\section{Multiplex magnetic bead-based assay}

Caco-2 cells were seeded in a 96 well plate (Ref. Number 3595 , Corning, NY) using $100 \mu \mathrm{l}$ of a suspension containing $8 \times 10^{4}$ cells per $\mathrm{ml}$ and incubated for $48 \mathrm{~h}$ at $37^{\circ} \mathrm{C}$ and $5 \% \mathrm{CO}_{2}$, to reach $80-90 \%$ confluence. Then, cells were exposed to samples and standards for $24 \mathrm{~h}$. DMSO $0.25 \%(\mathrm{v} / \mathrm{v})$ was included as vehicle control. After $24 \mathrm{~h}$ exposure of Caco-2 cells in the 96 well format (every exposure performed in triplicate, e.g., 3 wells per treatment), mild lysis of cells was achieved according to the manufacturer's instructions (QuantiGene 2.0 plex assay user manual, Affymetrix, The Netherlands). Briefly, the lysis mixture was diluted in nuclease-free water and $100 \mu \mathrm{l}$ were added per well. Plates were incubated for $18-22 \mathrm{~h}$ at $54^{\circ} \mathrm{C} \pm 1^{\circ} \mathrm{C}$, at $600 \mathrm{rpm}$ in a VorTemp ${ }^{\mathrm{TM}} 56$ Shaking Incubator (Thermo Fischer, The Netherlands), previously validated with a QuantiGene Incubator Temperature Validation Kit (Isogen, The Netherlands). The assay procedure consists of several hybridization, incubation, and washing steps using a plate magnet to capture the beads (Affymetrix, The Netherlands). After the final binding step, $130 \mu \mathrm{l}$ of washing buffer (provided in the kit) was added to the wells and plates were read in a xPonent ${ }^{\circledR} 3 \mathrm{D}$ machine (Luminex corp). The protocol was defined according to the manufacturer's instructions, i.e., sample size $100 \mu$ l, DD gate 5,000-25,000, timeout $45 \mathrm{~s}$, and bead event 100 . The total time needed from cell lysis to read-out is about $30 \mathrm{~h}$. Data analysis was performed as follows: MFI (median fluorescence intensity values) are provided from the $x$ Ponent ${ }^{\circledR}$ 3D machine in a .cvs file and were analyzed using Excel to calculate the average signal (avg MFI) for each gene (exposures were performed in triplicate). Then, the value obtained from each gene was divided by the value for the nor-

Tab. 2: Selected genes and representation of their expression as determined in the whole genome array studies Up- or down-regulated compared to a vehicle control: red arrows up represent genes that are up-regulated with log2 values higher than 0.7 and green arrows down are genes down-regulated with log2 values lower than -0.7 (Bodero et al., 2018b). The (*) represents up-regulation higher than a log2 value of 2.0 or down-regulation of a log2 value lower than -1.5 . The (-) represents log2 values between -0.4 and 0.4 , which are considered no significant effects on gene expression. ND, not determined.

\begin{tabular}{|l|l|l|l|l|l|}
\hline \multirow{2}{*}{ Gene } & \multicolumn{5}{|c|}{ Toxin Analogue } \\
\cline { 2 - 7 } & AZA-1 6.25 nM & OA 25nM & DTX-1 12.5 nM & YTX 12.8 nM & PTX-2 11.4 nM \\
\hline NPPB & - & - & $\downarrow^{*}$ & - & $\downarrow^{*}$ \\
\hline RGS16 & - & $\uparrow$ & $\uparrow^{*}$ & - & - \\
\hline DDIT4 & $\uparrow^{*}$ & $\uparrow$ & $\uparrow$ & $\uparrow$ & - \\
\hline CXCR4 & - & $\uparrow^{*}$ & $\uparrow^{*}$ & - & - \\
\hline TGFB2 & $\downarrow$ & $\downarrow$ & $\downarrow$ & - & - \\
\hline MAFB & - & $\uparrow^{*}$ & $\uparrow^{*}$ & - & - \\
\hline TNS4 & $\uparrow$ & - & $\uparrow$ & - & - \\
\hline C110rf96 & - & $\uparrow^{*}$ & $\uparrow^{*}$ & ND & ND \\
\hline CEACAM1 & $\uparrow$ & $\uparrow$ & $\uparrow$ & $\uparrow^{*}$ & - \\
\hline OSR2 & $\downarrow$ & - & $\uparrow$ & - & - \\
\hline MT1H & $\uparrow^{*}$ & $\uparrow$ & $\uparrow$ & - & - \\
\hline MT1G & $\uparrow^{*}$ & - & $\uparrow$ & $\uparrow$ & - \\
\hline TMEM179B & - & - & - & - & - \\
\hline CUL1 & - & - & - & - & - \\
\hline SH3BP2 & - & - & - & - & - \\
\hline
\end{tabular}


malization gene. Here we used the CUL1 gene (avg MFI gene of interest/avg MFI CUL1). Finally, for each test gene, we calculated the fold change by dividing the normalized value for the treated samples by the normalized value for the untreated sample, i.e., DMSO ((avg gene/avgcul1)/avg DMSO). Values were plotted in GraphPad Prism.

\section{Results}

Table 2 shows the twelve marker genes and three reference genes that were selected from the whole genome array studies where undifferentiated Caco-2 cells were exposed to OA, DTX-1, and AZA1 (Bodero et al., 2018b) and to YTX and PTX-2 (unpublished data). Genes were selected based on their response to the different toxins, e.g., NPPB is specifically down-regulated by PTX-2 and to some extent by DTX-1, while RGS16 is specifically up-regulated by DTX-1 and to some extent by OA. TMEM179B, CUL1, and SH3BP2 were not affected and used as reference genes. Moreover, besides OA, DTXs, AZAs, YTXs, and PTXs, other (nonregulated) marine biotoxins like the cyclic imines (CIs) might end up in the lipophilic extracts, however these toxins do not lead to clear effects on gene expression, even when tested at higher concentrations. Figure $\mathrm{S}^{1}{ }^{1}$ is an example of the CIs PnTX-E and SPX, and shows that these toxins do not result in clear effects on gene expression in exposed Caco- 2 cells.

\subsection{Development of a multiplex qRT-PCR detection method}

First, singleplex qRT-PCRs were performed in order to confirm the results of the whole genome array studies. For that, Caco-2 cells were exposed to 3 and $9 \mathrm{nM}$ of all the toxins, including the analogues, except for YTX, for which 12.5 and $37.5 \mathrm{nM}$ were used. These concentrations were used for all following experiments, as they result from a newly developed clean-up procedure for DSPs from mussels in combination with the regulatory limits (160 $\mu \mathrm{g} / \mathrm{kg}$ shellfish for OA, DTXs, PTX-2, and AZAs, and 3.75 $\mathrm{mg} / \mathrm{kg}$ shellfish for YTXs). Assuming 100\% toxin recoveries (Bodero et al., 2018a), the regulatory limits of OA, DTXs, AZAs, and PTX-2 will result in a final concentration of about $12 \mathrm{nM}$ in the well, while the regulatory limit of YTX will result in a final well concentration of about $200 \mathrm{nM}$. Figure 1 shows the relative expression level of each target gene for each toxin concentration, showing that each toxin except OA can be detected at a concen-

1 doi:10.14573/altex.1805291s

Fig. 1: Singleplex qRT-PCR results of the 5 selected marker genes NPPB, RGS16, DDIT4, CXCR4, and TGFB2 Values are shown as log2 relative quantity $(R Q)$ of the gene of interest.

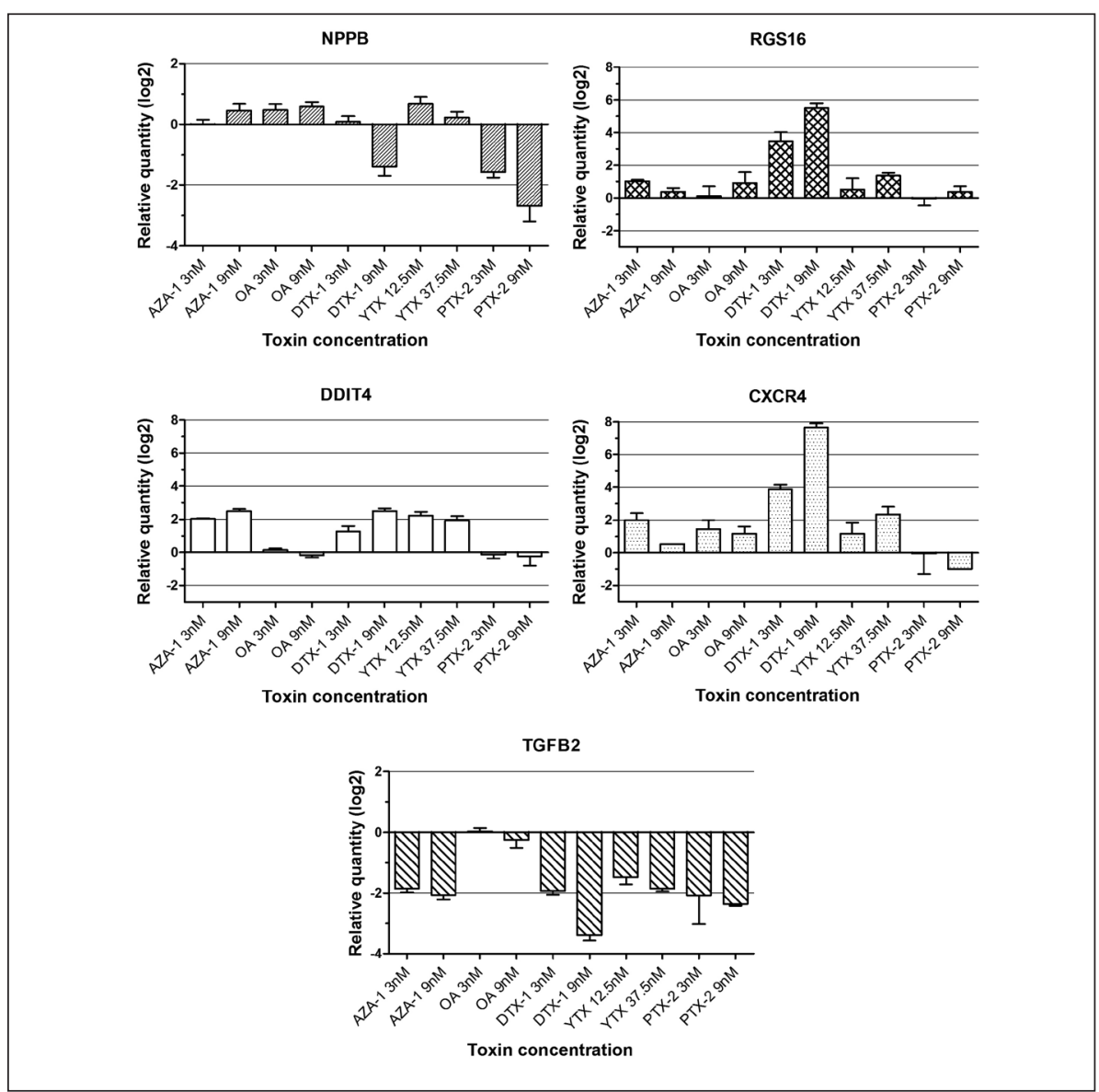




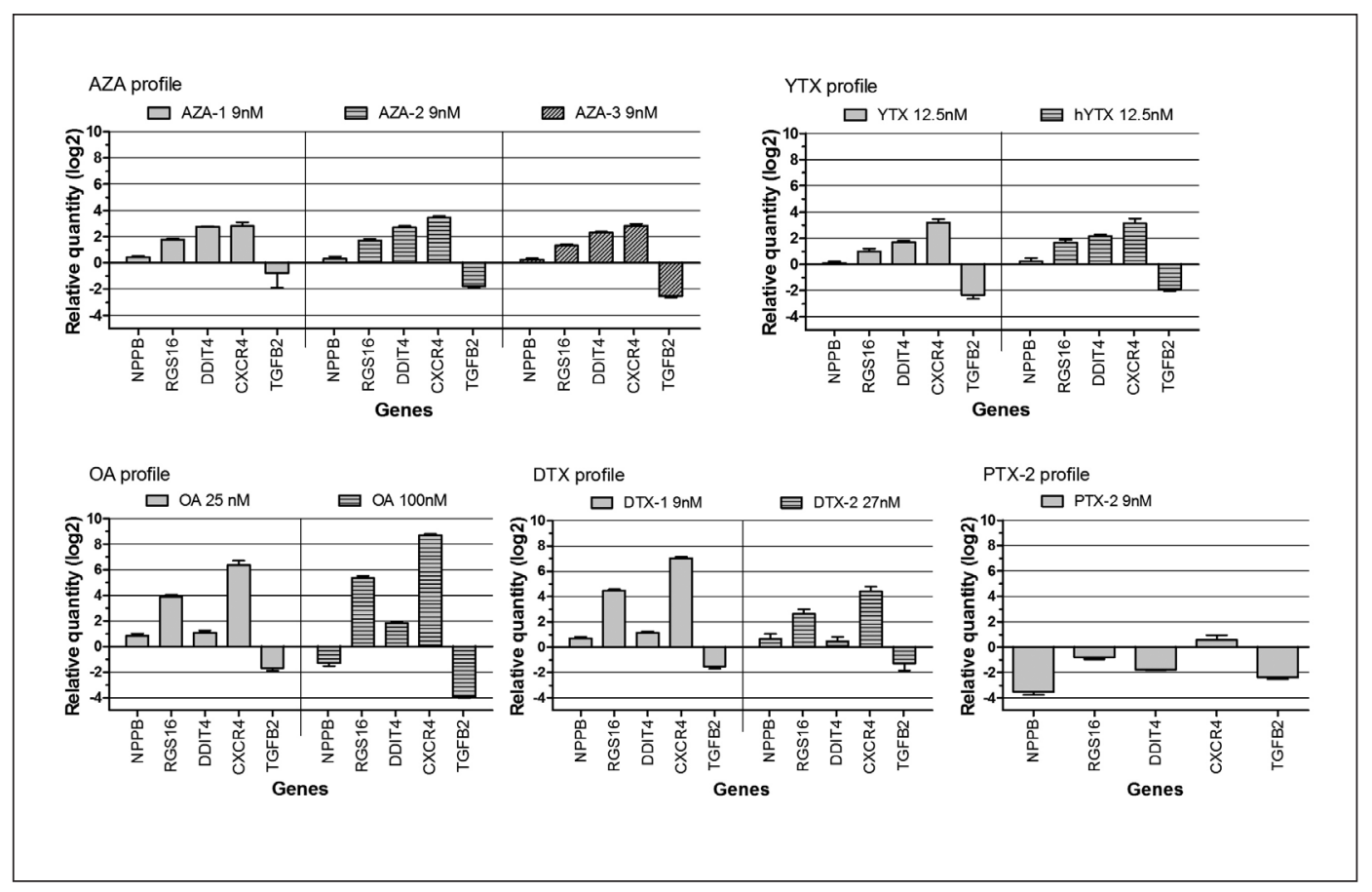

Fig. 2: Multiplex qRT-PCR profiles Profile A) AZAs and YTXs; profile B) OA/DTXs and profile C) PTX-2. Values are shown as log2 relative quantity $(R Q)$ of the gene of interest.

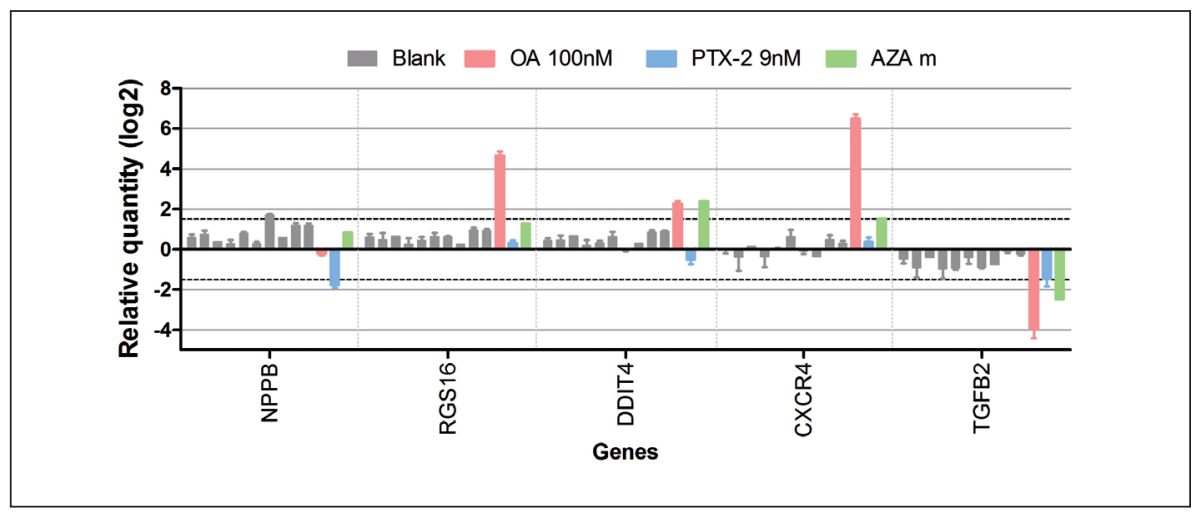

Fig. 3: Multiplex qRT-PCR profiles from blank shellfish extracts, standards, and a naturally contaminated mussel sample Caco-2 cells were exposed to 10 blank shellfish extracts, OA and PTX-2 standards, and an extract prepared from a mussel sample indicated as "AZA m" that is naturally contaminated with AZAs (1083 $\mu \mathrm{g} \mathrm{AZA-1-eq} \mathrm{kg-1).}$ Bars represent log2 values of the relative expression levels (RQ) of the genes.

tration relevant for enforcement purposes, i.e., a lower concentration (using a newly developed clean-up procedure) than resulting from its regulatory limit.

In general, genes in the singleplex qRT-PCR responded as expected from the whole genome array study (Tab. 2). The responses observed for AZA-1 at only $3 \mathrm{nM}$ are already clear and as expected, i.e., up-regulation of DDIT4 and down-regulation of TGFB2 and no effects on NPPB, RGS16, and CXCR4. As expected, all 5 genes responded to DTX-1 in a dose related way. There were no clear responses to $\mathrm{OA}$ at 3 and $9 \mathrm{nM}$. This was not surprising, as $25 \mathrm{nM}$ had been used in the whole genome array study because no effects of OA on gene expression could be observed at lower concentrations (data not shown). In spite of this, it was worthwhile to test 3 and $9 \mathrm{nM}$ OA using singleplex qRT-PCR to investigate whether singleplex qRT-PCR would be sensitive enough to detect $\mathrm{OA}$ at concentrations relevant for enforcement purposes. Note that the singleplex qRT-PCR is mainly developed to confirm samples that were positive in the neuro-2a bioassay but negative in the LC-MS/MS. For further experimentation, OA was employed at higher concentrations, i.e., 25 and $100 \mathrm{nM}$. PTX-2 was easily detected by the marker gene NPPB, which is specifically down-regulated by this toxin at low concentrations. YTX was detected by the up-regulation of DDIT4. It was remarkable that the YTX singleplex qRT-PCR profile was similar to that of AZAs, and also showed a down-regulation of TGFB2, which was not expected from the gene expression analysis. Another interesting finding is that the TGFB2 gene is downregulated by all toxins, except for OA at the (low) concentrations tested. The reference gene TMEM179B did not show any relevant expression (data not shown). It was decided to cut out TMEM179B as a reference gene, also because the use of all 6 fluorescent markers resulted in interference. 
As the singleplex qRT-PCR results showed that the 5 selected marker genes responded as expected and in a sensitive way, a multiplex qRT-PCR was developed using primers, probes, and dyes as shown in Table 1. Figure 2 shows that this newly developed multiplex qRT-PCR was able to detect all toxins, and all except $\mathrm{OA}$ at concentrations that are relevant for enforcement purposes. It was anticipated that toxin analogues would result in similar expression profiles and that therefore the multiplex qRT-PCR would be suited to detect the analogues as well. Therefore, also AZA-2, AZA-3, DTX-2, and hYTX were tested. Figure 2 shows that exposure to AZA-2 and AZA-3 indeed resulted in similar profiles as AZA-1 and at similar concentrations. Also, the profiles of OA, DTX-1, and DTX-2 were identical as were the profiles of YTX and hYTX. Table $\mathrm{S}^{1}$ shows a comparison of the expected and obtained results.
In order to further evaluate the performance of the newly developed multiplex qRT-PCR, ten blank mussel samples and a mussel sample contaminated with AZAs (1083 $\left.\mu \mathrm{g} \mathrm{AZA-eq} \mathrm{kg}^{-1}\right)$, all according to the EURL LC-MS/MS method, were tested. Figure 3 shows that the extracts of the blank mussel samples did not affect the expression of any of the selected marker genes, while mussel contaminated with AZAs resulted in a "perfect" AZA/ YTX-profile. Standards of OA and PTX-2 were used as positive controls and also resulted in the expected profiles.

To further increase the capacity to detect and identify the toxins by multiplex qRT-PCR, especially for the discrimination between the presence of AZAs or YTXs, a second multiplex qRT-PCR could have been developed. Instead, it was decided to analyze mRNA expression by multiplex magnetic beadbased assay.

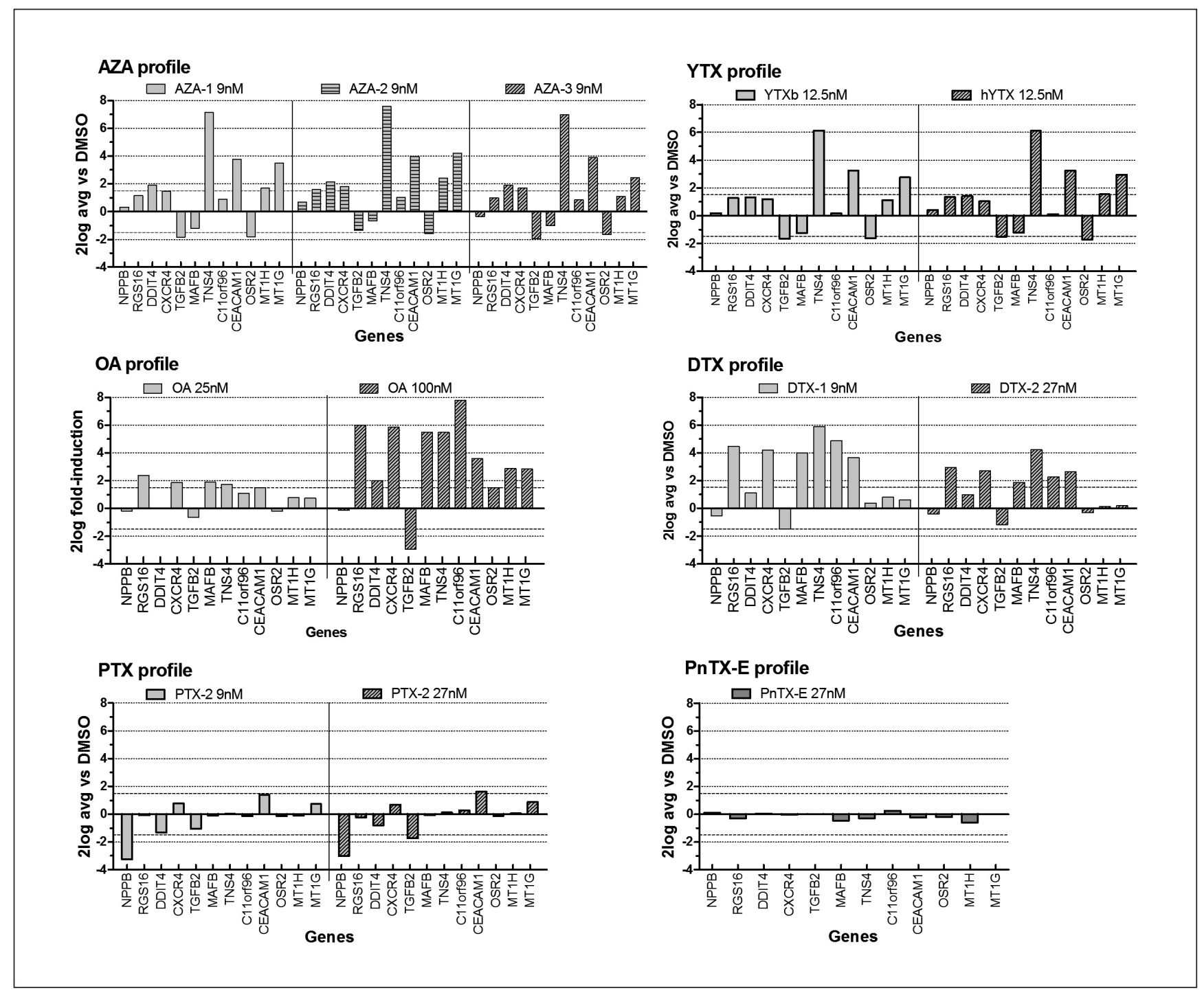

Fig. 4: Profiles per toxin obtained from the multiplex magnetic bead-based assay

Caco-2 cells were exposed to OA, DTX-1, DTX-2, AZA-1, AZA-2, AZA-3, YTX, hYTX, PTX-2, and PnTX-E. Bars represent log2 of fold-induction values of each of the 12 marker genes. Positive values represent up-regulation, negative values represent down-regulation. Spotted lines indicate "noise", which is defined by expression levels between 1.5 and -1.5 (log2 values). 


\subsection{Development of a multiplex magnetic bead-based assay for 14 genes}

The multiplex magnetic bead-based assay enables the examination of up to 100 genes, and it is based on the direct detection of the mRNA present in the sample, making it less labor intensive, i.e., no need for RNA purification, reverse transcription, or amplification. Besides the 5 genes selected for multiplex PCR, more genes were selected from the whole genome array experiments, i.e., 7 marker genes and 2 more reference genes (Tab. 2). The multiplex magnetic bead-based assay uses magnetic beads coupled with DNA probes. These specific probes hybridize with a cognate mRNA present in the sample. The fluorescent signal associated with each specific bead is read on a Luminex ${ }^{\circledR}$ flow cytometer, where the equipment detects the specific bead, representing the gene, and the fluorescent signal attached to that bead, indicating the amount of cognate mRNA in the sample. Median fluorescence intensities (MFIs) are measured and used to calculate relative gene expression levels.

The same toxins and toxin analogues as described above for the multiplex qRT-PCR method (5-plex) were tested in this multiplex magnetic bead-based 14-plex assay, i.e., OA, DTX-1, DTX2, AZA-1, AZA-2, AZA-3, YTX, hYTX, and PTX-2. Pinnatoxin (PnTX-E) was used as a negative control, since PnTX-E hardly affected the gene expression levels in Caco-2 (Fig. S1 ${ }^{1}$ ). Figure 4 shows the results for all the analogues and the 12 marker genes selected for this method (see also Tab. S2 ${ }^{1}$ ). These data also revealed three clear profiles, i.e., an OA/DTXs profile, an AZAs/ YTXs profile, and a PTX-2 profile. As expected, PnTX-E did not elicit any specific responses at the gene expression level. When looking at more data in more detail (Fig. S2 ${ }^{1}$ ), it also becomes clear that in the concentration ranges tested, i.e., AZAs 3-9 nM, DTXs and PTX-2 3-27 nM, OA 3-100 nM, and YTXs 12.5-37.5 $\mathrm{nM}$, the OA/DTX profile shows clear dose-response effects. It also shows that using this test format it is also not possible to detect gene expression at low concentrations of OA, i.e., 3-9 nM. OA starts to affect gene expression at $25 \mathrm{nM}$ and results in a clear profile at $100 \mathrm{nM}$, similar to the profile obtained with DTX-1 at $9 \mathrm{nM}$, indicating that DTX-1 is about 4 times more potent than $\mathrm{OA}$ and in line with the relative potencies as observed in the neuro-2a bioassay (Bodero et al., 2018a,b). Thus, also on the beadbased format it is not possible to detect $\mathrm{OA}$ at concentrations relevant for enforcement purposes. The DTX-2 response is lower than that of DTX-1, which is expected as DTX-2 is less potent than DTX-1 (FAO/WHO, 2016; Aune et al., 2007; Bodero et al., 2018a). At a level relevant for enforcement purposes, $27 \mathrm{nM}$, the DTX-2 profile is identical to that of DTX-1 at $9 \mathrm{nM}$. Just

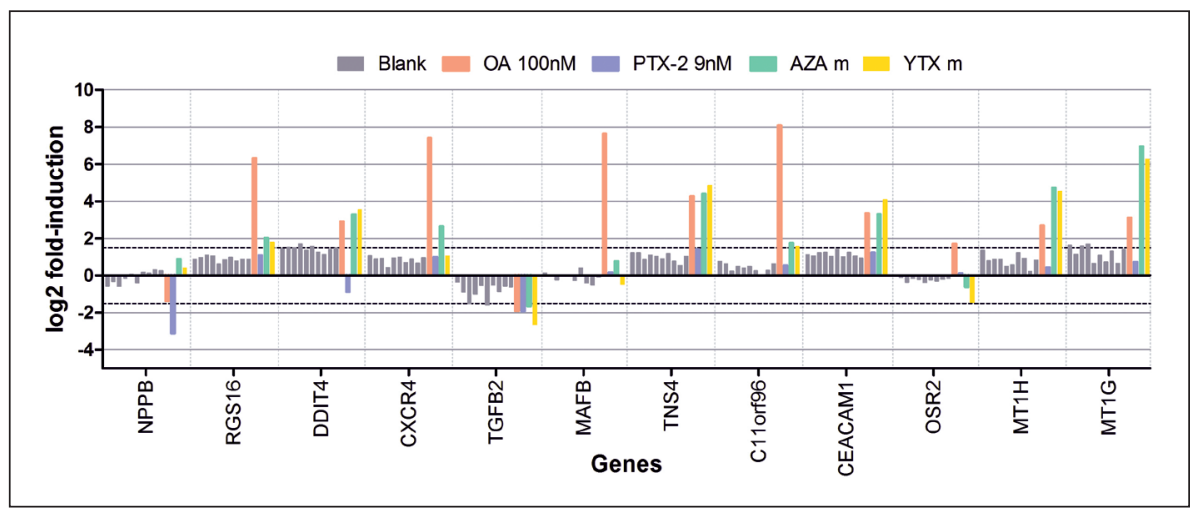

Fig. 5: Multiplex magnetic beadbased assay on blank mussel samples, standards, and naturally contaminated mussels Caco-2 cells were exposed to 10 blank mussel samples (grey bars), OA (red bar) and PTX-2 (blue bar) standards, and mussels naturally contaminated with AZA (green bar) and with YTX (orange bar). Spotted lines indicate "noise", which is defined by expression levels between -1.5 and 1.5 (log2 values).

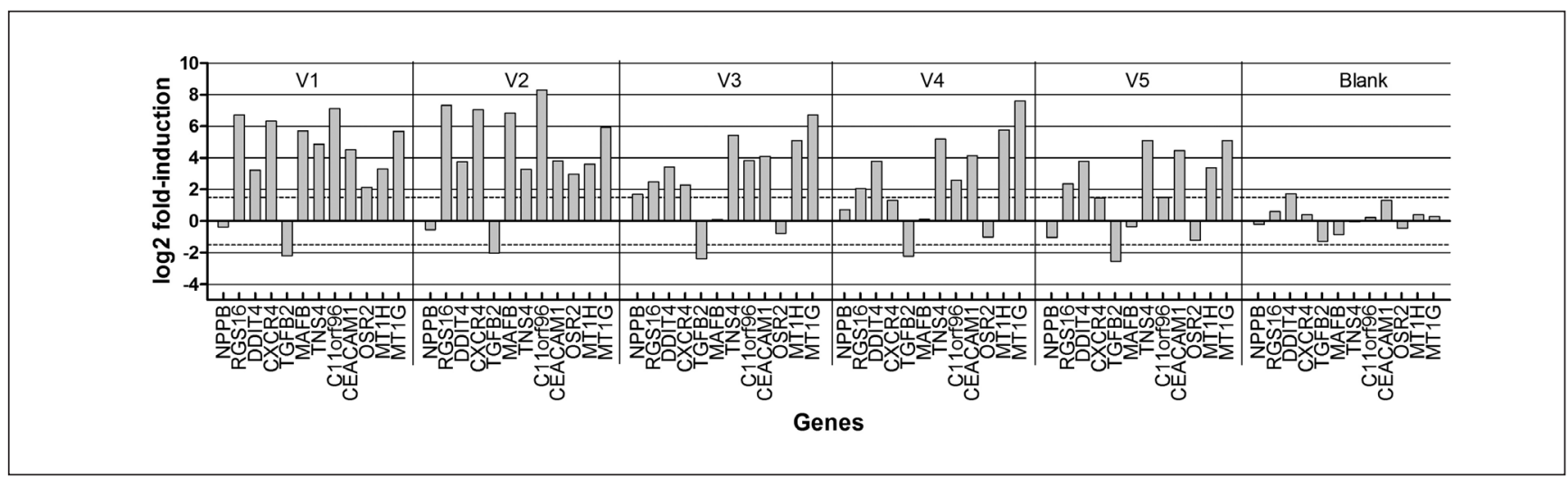

Fig. 6: Multiplex magnetic bead-based assay on validation samples

Caco- 2 cells were exposed to 5 contaminated and one blank mussel sample. Spotted lines indicate "noise", which is defined by expression levels between log2 values 1.5 and -1.5 . 
Tab. 3: LC-MS/MS results from the 5 validation samples depicted in Figure 6 Data from van den Top et al. (2011).

\begin{tabular}{|c|c|c|c|c|c|}
\hline \multirow[t]{2}{*}{ Sample } & \multirow[t]{2}{*}{ OA, DTXs, PTX-2 (1) } & \multirow[t]{2}{*}{ AZAs (2) } & \multirow[t]{2}{*}{ YTXs ${ }^{(3)}$} & \multicolumn{2}{|c|}{ Outcome } \\
\hline & & & & neuro-2a assay & Luminex \\
\hline V1 & 123 & & 481 & positive & OA/DTX \\
\hline V2 & 275 & 2422 & & positive & OA/DTX \\
\hline V3 & & 32.4 & & positive & AZA/YTX \\
\hline V4 & & & 770 & positive & AZA/YTX \\
\hline V5 & & & 620 & positive & AZA/YTX \\
\hline
\end{tabular}

${ }^{(1)} \mu \mathrm{g} \mathrm{OA}$-eq kg-1 $^{-1}{ }^{(2)} \mu \mathrm{g} \mathrm{AZA-1}$ eq kg-1, ${ }^{(3)} \mu \mathrm{g}$ YTX-eq kg-1

as the DTXs, the AZAs, YTXs, and PTX-2 can be detected at relevant concentrations for enforcement purposes. However, the profiles for AZAs and YTXs are still identical. The TNS4, OSR2, and MT1H genes had been added to distinguish the AZAs from the YTXs (Tab. 2), but like TGFB2 in the multiplex qRT-PCR, the YTXs caused the same effects on these three genes as the AZAs. In order to rule out that YTX or AZA toxin standard were switched, the YTX, AZA-1, and DTX-1 stock solutions in DM$\mathrm{SO}$ were checked by LC-MS/MS analysis. Figure $\mathrm{S} 3^{1}$ shows the mass chromatograms, demonstrating that YTX and AZA were not switched, and that these standards are of the quality expected for certified reference standards.

\subsection{Testing blanks and positive shellfish samples with the multiplex magnetic bead-based assay}

Figure 5 shows the outcome of the multiplex magnetic beadbased assay testing extracts prepared from ten blank mussel samples, the same "AZA mussel sample" used previously for the multiplex qRT-PCR, and a mussel sample contaminated with YTXs (330 $\mu$ g YTX-eq kg-1), as well as an OA and PTX-2 standard. The results demonstrate that blank samples (indicated in grey) do not lead to a substantial effect on the gene expression of the selected markers, i.e., all induction values are between 1.5 and $-1.5 \log 2$ values, which are considered as "noise". When another set of 20 blank samples was tested, the outcomes were the same, i.e., no marker genes had induction factors above $\log 2$ values (see Fig. S4 ${ }^{1}$ ). The positive controls, i.e., OA $100 \mathrm{nM}$ and PTX-2 $9 \mathrm{nM}$, showed the expected and same profiles as described above in the multiplex qRT-PCR results (Fig. 3). As expected from testing pure standards (Fig. 4), the AZA and YTX contaminated mussel samples resulted in the expected AZA/YTX profile of the selected marker genes.

In addition, 5 shellfish samples with different concentrations and/or a mix of lipophilic marine biotoxins that were used in previous validation studies (van den Top et al., 2011), were tested. Their toxin levels are displayed in Table 3. Figure 6 shows the outcome of the multiplex magnetic bead-based assay. Again, the blank mussel sample did not induce a substantial effect on the gene expression of the selected markers, while the 5 contaminated samples did. The interpretation of the profiles obtained with these contaminated samples becomes a bit more complicated, as the samples contain mixtures of the toxins. However, it is possible to differentiate an AZA/YTX profile and an OA/DTX profile from the samples. According to the profile, samples V2 and V3 are more likely to be contaminated with OA/DTX toxins, while samples V5, V6, and V8 show a more AZA/YTX toxin-like profile. The latter is correct, but V2 and V3 do not only contain DTXs, but respectively also YTXs and AZAs. It is interesting to mention that sample V5 results in an AZA/YTX profile but is only contaminat-

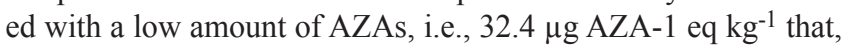
assuming $100 \%$ recovery, would result in an equivalent of $2 \mathrm{nM}$ AZA-1 in the well. As the sample was positive in the neuro-2a bioassay (Bodero et al., 2018a) and resulted in a clear profile in the multiplex magnetic bead-based assay, this sample might also contain an unknown AZA or YTX analogue.

\section{Discussion}

Worldwide, the mouse bioassay has been the main method to detect shellfish poisons in samples for human consumption for decades and is still used in surveillance programs in many countries. Chemical analytical methods have been developed and proven suitable for the detection of known toxins, but countries with high occurrences of shellfish toxins in their coastal waters are still wary of relying solely on these. One concern is the lack of standards for the known toxins. Another concern is that new toxins may appear that would be missed by chemical analysis. In that regard, cell-based bioassays are a promising addition. Especially the neuro-2a bioassay has been shown to be very useful for the broad detection of marine biotoxins, i.e., DSPs, NSPs, and PSPs (Nicolas et al., 2014; Reverte et al., 2014; Cañete and Diogène, 2010). When using the neuro-2a bioassay for the broad detection of DSPs, samples screened negative are safe to consume and positive samples can be confirmed by analytical chemical methods. It has been demonstrated that this is a fruitful approach (Bodero et al., 2018a). However, in case a positive sample cannot be confirmed by chemical analysis, indicating the presence of an unknown toxin, additional analysis is needed. For 
this, a second bioassay that is able to confirm the presence of such "DSP-like toxins" and also to identify the kind of DSP toxin present, would be very helpful. If this second bioassay also indicates the presence of a toxin, a bioassay-directed approach can be followed to identify this unknown active (Rijk et al., 2009). Figure 7 is a schematic view of the proposed strategy.

In the present study, specific effects of the DSPs on the gene expression in Caco-2 cells were used to develop a method that is able to distinguish these toxins. Previous gene expression studies identified three toxin profiles: i) OA/DTXs, ii) AZAs (and YTXs to some degree), and iii) PTX-2. Marker genes were selected, and two multiplex assays were developed, i.e., a multiplex qRTPCR (5-plex) method and a multiplex magnetic bead-based assay (14-plex).

The multiplex qRT-PCR method, using 5 markers only, was able to determine the presence of each of all regulated DSPs, including their analogues and thus potentially also unknowns, in extracts prepared from mussel samples. The profiles enabled the discrimination between the presence of OA/DTXs, AZAs, and PTX-2, but the toxin profiles were not sufficiently specific to discriminate between the presence of AZAs and YTXs. As OA and DTX belong to the same group, have a similar mode of action, and only differ in their potency, it is not possible to distinguish them with these effect-based bioassays (Bodero et al., 2018b; Ferron et al., 2014). A multiplex magnetic bead-based assay, i.e., using specific probes that hybridize with the selected marker mRNAs and which are attached to Luminex ${ }^{\circledR}$ magnetic beads, allowed us to multiplex 14 genes in one reaction and resulted in more clear and complete toxin profiles, showing similar or higher induction factors than obtained by qRT-PCR. However, the profiles still did not allow discrimination between AZAs and YTXs, or a more sensitive detection of OA. The TNS4, OSR2, and MT1H genes had been added to the multiplex magnetic beadbased assay to distinguish the AZAs from the YTXs (Tab. 2), but just like TGFB2 in the multiplex qRT-PCR, the YTXs induced the same effect on these three genes as the AZAs did. The selection of those genes was done based on gene expression analysis performed on a microarray. Probably, this YTX array did not work as accurately as those used for OA, DTX-1, AZA-1, and PTX-2, as the standards were checked by LC-MS/MS and were pure and not switched. Taken together, both methods were able to confirm the presence of DSPs and also to (partly) identify the kind of DSP toxin present.

Besides the DSPs tested here, also any neurotoxic brevetoxins will be present in the prepared extracts (lipophilic), while PSPs and ASPs (hydrophilic) will not end up in the lipophilic sample extracts. Effects on gene expression by brevetoxins and respective transcriptomics data are scarce (Walsh et al., 2003; Murrell and Gibson, 2011). However, the brevetoxins were not included in the present study, as the neuro-2a bioassay is already able to discriminate between the presence of DSPs and the neurotoxic brevetoxins, i.e., DSPs can be detected without addition of ouabain and veratridine, while the brevetoxins can only be detected in the neuro-2a bioassay by adding low concentrations of ouabain and veratridine (Manger et al., 1995; Dickey et al., 1999). In addition, it is shown that the nonregulated CIs like PnTX-E and SPX,

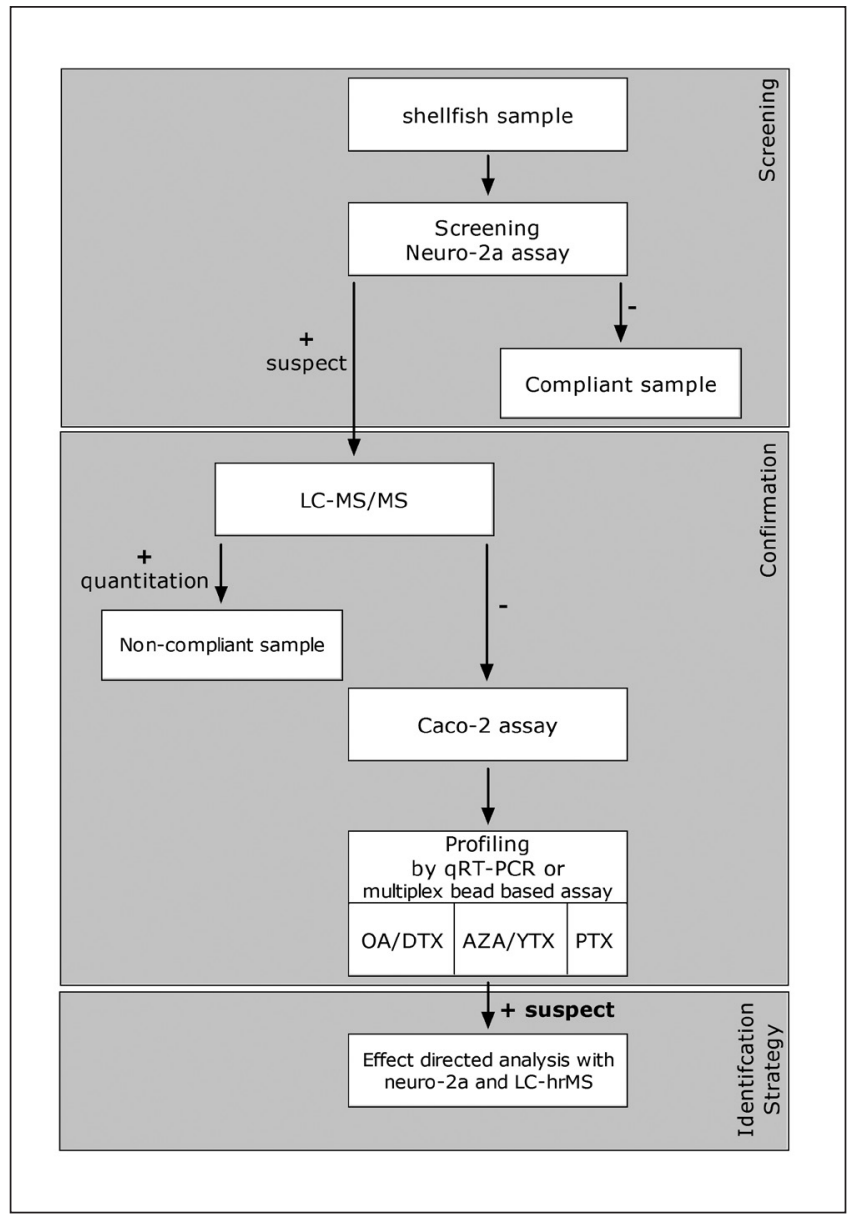

Fig. 7: Proposed strategy for the broad screening of shellfish for the presence of DSPs

The strategy uses the neuro-2a bioassay for broad screening/ detection (nonspecific cytotoxicity), analytical chemical analyses (LC-MS/MS) for the confirmation of known toxins, and the multiplex magnetic bead-based assay (specific mRNAs) or qRT-PCR for the confirmation of unknown toxins in case suspect neuro-2a outcomes cannot be explained by LC-MS/MS analysis. When the presence of an unknown active is confirmed by the second bioassay, a bioassay directed fractionation approach can be used to identify the new toxin.

which can also end up in the prepared lipophilic extracts, do not elicit clear effects on gene expression in Caco-2 cells (Fig. S1 ${ }^{1}$ ). It cannot be fully ruled out that an unknown compound leads to a positive neuro-2a bioassay outcome that cannot be confirmed by either the LC-MS/MS or the multiplex assays based on gene expression of Caco-2 cells. It is also impossible to address upfront whether it could lead to human intoxications, e.g., diarrhoea. However, in case of an DSP outbreak (humans with, e.g. diarrhoea), the bioassay-directed fractionation approach can still be used, despite the absence of a confirmed Caco-2 effect.

In a previous study, it was shown that the use of an additional n-hexane washing-step improved the clean-up of the lipophilic 
marine biotoxins by eliminating false-positives in the neuro-2a bioassay due to matrix effects (Bodero et al., 2018a). The present study shows that this clean-up also results in extracts that can be used to expose the Caco- 2 cells, as blank samples did not affect the gene expression patterns, while contaminated samples resulted in the expected profiles. The multiplex magnetic bead-based assay allowed us to multiplex 14 genes in one reaction. The method performs well and is less labor-intensive than the multiplex qRT-PCR method, but the costs are higher. Both multiplex methods work, and laboratories involved in monitoring can make their own choice, as the Caco- 2 cells are easily available.

Although more testing and validation are required, an approach where the neuro-2a bioassay is used for the broad screening of lipophilic marine biotoxins and LC-MS/MS analysis is used to confirm and identify the toxins present in the positive samples, supplemented with a multiplex assay based on the expression of marker genes in Caco-2 cells in case positive neuro-2a samples cannot be confirmed by LC-MS/MS analysis (Fig. 7), is very promising for ultimately replacing the mouse bioassay.

\section{References}

Aune, T., Larsen, S., Aasen, J. A. B. et al. (2007). Relative toxicity of dinophysistoxin-2 (DTX-2) compared with okadaic acid, based on acute intraperitoneal toxicity in mice. Toxicon 49, 1-7. doi:10.1016/j.toxicon.2006.07.033

Bodero, M., Bovee, T. F. H., Wang, S. et al. (2018a). Screening for the presence of lipophilic marine biotoxins in shellfish samples using the neuro-2a bioassay. Food Addit Contam Part A Chem Anal Control Expo Risk Assess 35, 351-365. doi:10. 1080/19440049.2017.1368720

Bodero, M., Hoogenboom, R. L. A. P., Bovee, T. F. H. et al. (2018b). Whole genome mRNA transcriptomics analysis reveals different modes of action of the diarrheic shellfish poisons okadaic acid and dinophysis toxin-1 versus azaspiracid-1 in Caco-2 cells. Toxicol In Vitro 46, 102-112. doi:10.1016/j. tiv.2017.09.018

Botana, L. M. (2012). A perspective on the toxicology of marine toxins. Chem Res Toxicol 25, 1800-1804. doi:10.1021/ tx3001863

Bovee, T. F., Hendriksen, P. J., Portier, L. et al. (2011). Tailored microarray platform for the detection of marine toxins. Environ Sci Technol 45, 8965-8973. doi:10.1021/es2011385

Campbell, K., Vilariño, N., Botana, L. M. et al. (2011). A European perspective on progress in moving away from the mouse bioassay for marine-toxin analysis. Trends Anal Chem 30, 239-253. doi:10.1016/j.trac.2010.10.010

Cañete, E. and Diogène, J. (2008). Comparative study of the use of neuroblastoma cells (Neuro-2a) and neuroblastoma $\times$ glioma hybrid cells (NG108-15) for the toxic effect quantification of marine toxins. Toxicon 52, 541-550. doi:10.1016/j. toxicon.2008.06.028

Cañete, E. and Diogène, J. (2010). Improvements in the use of neuroblastomaxglioma hybrid cells (NG108-15) for the toxic effect quantification of marine toxins. Toxicon 55, 381-389. doi:10.1016/j.toxicon.2009.08.017
Ciminiello, P. and Fattorusso, E. (2006). Bivalve molluscs as vectors of marine biotoxins involved in seafood poisoning. In G. Cimino and M. Gavagnin (eds.), Molluscs. Berlin, Heidelberg, Germany: Springer. doi:10.1007/978-3-540-30880-5_3

Combes, R. D. (2003). The mouse bioassay for diarrhetic shellfish poisoning: A gross misuse of laboratory animals and of scientific methodology. Altern Lab Anim 31, 595-610.

Denisson, N. and Anderson, D. B. (2007). The 3 'R's approach to marine biotoxin testing in the UK. AATEX 14, Spec Issue, 757-761. http://altweb.jhsph.edu/wc6/paper757.pdf

Dickey, R., Jester, E., Granade, R. et al. (1999). Monitoring brevetoxins during a Gymnodinium breve red tide: Comparison of sodium channel specific cytotoxicity assay and mouse bioassay for determination of neurotoxic shellfish toxins in shellfish extracts. Nat Toxins 7, 157-165. doi:10.1002/(SICI)15227189(199907/08)7:4<157::AID-NT52>3.0.CO;2-\#

EFSA (2009). Scientific Opinion of the Panel on Contaminants in the Food Chain on a request from the European Commission on Marine Biotoxins in Shellfish - Summary on regulated marine biotoxins. EFSA Journal 1306, 1-23. doi:10.2903/j. efsa.2009.1306

EU - European Union (2011). Commission Regulation (EU) No 15/2011 of 10 January 2011 amending Regulation (EC) No $2074 / 2005$ as regards recognised testing methods for detecting marine biotoxins in live bivalve molluscs. Off $J$ Eur Union $L$ 6, 3-6.

FAO - Food and Agriculture Organization of the United Nations (2004). Marine Biotoxins. FAO Food and Nutrition Paper 80. http://www.fao.org/docrep/007/y5486e/y5486e00.htm

FAO/WHO (2016). Technical paper on Toxicity Equivalency Factors for Marine Biotoxins Associated with Bivalve Molluscs.

Ferron, P. J., Hogeveen, K., Fessard, V. and Le Hégarat, L. (2014). Comparative analysis of the cytotoxic effects of okadaic acid-group toxins on human intestinal cell lines. Mar Drugs 12, 4616-4634. doi:10.3390/md12084616

Garthwaite, I. (2000). Keeping shellfish safe to eat: A brief review of shellfish toxins, and methods for their detection. TrendsFoodSciTech 11,235-244. doi:10.1016/S0924-2244(01) 00006-1

Gerssen, A., Pol-Hofstad, I. E., Poelman, M. et al. (2010a). Marine toxins: Chemistry, toxicity, occurrence and detection, with special reference to the Dutch situation. Toxins (Basel) 2, 878-904. doi:10.3390/toxins2040878

Gerssen, A., van Olst, E. H., Mulder, P. P. and de Boer, J. (2010b). In-house validation of a liquid chromatography tandem mass spectrometry method for the analysis of lipophilic marine toxins in shellfish using matrix-matched calibration. Anal Bioanal Chem 397, 3079-3088. doi:10.1007/s00216-010-3886-2

Hess, P., Grune, B., Anderson, D. B. et al. (2006). Three Rs approaches in marine biotoxin testing. The report and recommendations of a joint ECVAM/DG SANCO workshop (ECVAM Workshop 54). Altern Lab Anim 34, 193-224.

Ledreux, A., Serandour, A. L., Morin, B. et al. (2012). Collaborative study for the detection of toxic compounds in shellfish extracts using cell-based assays. Part II: Application to shell- 
fish extracts spiked with lipophilic marine toxins. Anal Bioanal Chem 403, 1995-2007. doi:10.1007/s00216-012-6029-0

Manger, R. L., Leja, L. S., Lee, S. Y. et al. (1995). Detection of sodium channel toxins: Directed cytotoxicity assays of purified ciguatoxins, brevetoxins, saxitoxins, and seafood extracts. J AOAC Int 78, 521-527.

Murrell, R. N. and Gibson, J. E. (2011). Brevetoxin 2 alters expression of apoptotic, DNA damage, and cytokine genes in Jurkat cells. Hum Exp Toxicol 30, 182-191. doi:10.1177/0960327110372644

Nicolas, J., Hendriksen, P. J., Gerssen, A. et al. (2014). Marine neurotoxins: State of the art, bottlenecks, and perspectives for mode of action based methods of detection in seafood. Mol Nutr Food Res 58, 87-100. doi:10.1002/mnfr.201300520

Reverte, L., Solino, L., Carnicer, O. et al. (2014). Alternative methods for the detection of emerging marine toxins: Biosensors, biochemical assays and cell-based assays. Mar Drugs 12, 5719-5763. doi: $10.3390 / \mathrm{md} 12125719$

Rijk, J. C., Bovee, T. F., Wang, S. et al. (2009). Detection of anabolic steroids in dietary supplements: The added value of an androgen yeast bioassay in parallel with a liquid chromatography-tandem mass spectrometry screening method. Anal Chim Acta 637, 305-314. doi:10.1016/j.aca.2008.09.014

Rossini, G. P. (2005). Functional assays in marine biotoxin detection. Toxicology 207, 451-462. doi:10.1016/j.tox.2004.10.012

Serandour, A. L., Ledreux, A., Morin, B. et al. (2012). Collaborative study for the detection of toxic compounds in shellfish extracts using cell-based assays. Part I: Screening strategy and pre-validation study with lipophilic marine toxins. Anal Bio- anal Chem 403, 1983-1993. doi:10.1007/s00216-012-6028-1 Stewart, I. and McLeod, C. (2014). The laboratory mouse in routine food safety testing for marine algal biotoxins and harmful algal bloom toxin research: Past, present and future. $J A O A C$ Int 97, 356-372. doi:10.5740/jaoacint.SGEStewart

van den Top, H. J., Gerssen, A., McCarron, P. and van Egmond, H. P. (2011). Quantitative determination of marine lipophilic toxins in mussels, oysters and cockles using liquid chromatography-mass spectrometry: Inter-laboratory validation study. Food Addit Contam Part A Chem Anal Control Expo Risk Assess 28, 1745-1757. doi:10.1080/19440049.2011.608382

Van Dolah, F. M. and Ramsdell, J. S. (2001). Review and assessment of in vitro detection methods for algal toxins. $J A O A C$ Int 84, 1617-1625.

Walsh, P. J., Bookman, R. J., Zaias, J. et al. (2003). Toxicogenomic effects of marine brevetoxins in liver and brain of mouse. Comp Biochem Physiol B Biochem Mol Biol 136, 173 182. doi:10.1016/S1096-4959(03)00223-9

\section{Conflict of interest}

The authors declare no conflict of interest.

\section{Acknowledgements}

Dr Arjen Gerssen and Mirjam Klijnstra from RIKILT, The Netherlands are thanked for the additional LC-MS/MS analysis of the toxin standards and Dr Arjen Gerssen also for critically reading the manuscript. 